\title{
Extensive assessment and evaluation methodologies on assistive social robots for modelling human-robot interaction - A review
}

\author{
Doreen Ying Ying Sim ${ }^{\mathrm{a}, *}$, Chu Kiong Loo ${ }^{\mathrm{b}}$ \\ ${ }^{a}$ Faculty of Cognitive Science and Human Development, Universiti Malaysia Sarawak, 94300 Kota Samarahan, Sarawak, Malaysia \\ ${ }^{\mathrm{b}}$ Faculty of Computer Science and Information Techonology, University of Malaya, Wilayah Persekutuan, Kuala Lumpur, Malaysia
}

\section{A R T I C L E I N F O}

\section{Article history:}

Received 15 August 2013

Received in revised form 28 November 2014

Accepted 4 December 2014

Available online 24 December 2014

\section{Keywords:}

Extensive evaluation

Assessment

Human-Robot Interaction (HRI)

Assistive social robot

A better modelling approach

New vision

\begin{abstract}
A B S T R A C T
Assessment and evaluation methodologies as well as combinations of them, for modelling of Human-Robot Interaction (HRI), are reviewed extensively and thoroughly in this paper. However, based on the types of robots and the kinds of interactions involved in the modelling of HRI, we concentrate just on the assistive social robot types. A comprehensive review has been done on each of these extensive evaluation and assessment methodologies applied for testing the usability of assistive social robots, user acceptance towards robots and robot acceptance in terms of behavioural adaptation during the HRI. The evaluation methodologies are reviewed based on the primary and non-primary basis, while the assessment methodologies are reviewed based on the type(s) of modelling approaches. We then discussed the weaknesses, strengths and uniqueness of each type of the past research work done on the evaluation and assessment methodologies. Comparison and contrast tables are also illustrated. Lastly, this paper provides our recommended directions, new vision, as well as our inspirations and new insights for future researches by highlighting the key areas for enhancing each of the past evaluation and assessment methodologies so that a better modelling approach for HRI can be achieved. Contributions of this review paper are also discussed thoroughly.
\end{abstract}

(c) 2014 Elsevier Inc. All rights reserved.

\section{Introduction}

Assessing acceptance in robots needs a methodology or a series of methodologies that is often used to measure the willingness of people to use a technology. This needs a type of modelling, which is always known as the Technology Acceptance Modelling (TAM) [20,21,23,55,57,61,63,135]. Nowadays, significant increase in the elderly population and the increased shortage of labour, as well as the explosion of costs in our daily expenses, have posed extreme challenges to our society $[55,61,63,152]$. However, how many research projects can explore the applicability of technological advances such as Intelligent Systems that enable people to live independently? In this paper, we discussed our notion of the concepts 'social' and 'assistive' within the context of robots used by people nowadays. So, the two main robot types that we review are of 'social' and 'assistive' (see Fig. 1). Then, we deepen our understanding of these concepts and review the examples of the developments of these two main robot types, mainly involved in the long-term modelling of Human-Robot Interaction

\footnotetext{
* Corresponding author. Tel.: +60 82 244942; fax: +60 82332641 .

E-mail address: dsdoreenyy@gmail.com (D.Y.Y. Sim).
} 